\title{
Analisis Customer Satisfying dan Knowledge Sharing Dalam Optimalisasi Formulasi Promotion Pemasaran Produk Lokal di Yogyakarta dan Palangka Raya
}

\author{
Vivy Kristinae \\ Program Studi Manajemen \\ Universitas Palangka Raya \\ Palangka Raya, Indonesia \\ e-mail: vivi.cristina@feb.upr.ac.id
}

Riwayat Artikel Tanggal diajukan: 11 November 2021

Tanggal diterima : 13 Desember 2021

Tanggal dipublikasikan: 15 Desember 2021

\begin{abstract}
Abstrak
Riset di bidang manajemen pemasaran untuk mengoptimalkan perumusan promosi dari kepuasan pelanggan dan berbagi pengetahuan dalam mewujudkan kesejahteraan ekonomi pelaku usaha produk lokal. Penelitian dilakukan di dua kota di Indonesia yang memiliki budaya dengan produk batik sebagai ikon estetika daerah dalam memenuhi kebutuhan pelanggan. Batik memiliki daya tarik dan filosofi yang merupakan warisan budaya, secara ekonomi memiliki nilai tambah untuk memajukan daerah dari peningkatan pendapatan. Teori penelitian SDL dalam memberikan strategi untuk meningkatkan kualitas layanan dalam hal promosi berdasarkan kebutuhan pelanggan. Penelitian dilakukan terhadap 300 pengusaha batik di Yogyakarta dan di Palangka Raya. Jenis penelitian kuantitatif dengan alat statistik SPSS 24.0 menunjukkan hasil positif yang signifikan dari kepuasan pelanggan dan berbagi pengetahuan meningkatkan optimalisasi promosi pemasaran sebesar $71 \%$. Implikasi penelitian sebagai strategi pemasaran dalam meningkatkan pendapatan pelaku usaha produk lokal, dari optimalisasi promosi pemasaran untuk kesejahteraan ekonomi pelaku usaha.
\end{abstract}

Kata Kunci : Kepuasan Pelanggan;Berbagi Pengetahuan; Formulasi Promosi;

Produk Batik

Pengutipan:

Kristinae, V.

(2021),Analisis

Customer

Satisfying dan

Knowledge

Sharing Dalam

Optimalisasi

Formulasi

Promotion

Pemasaran

Produk Lokal di

Yogyakarta dan

Palangka Raya,

Jurnal Pendidikan

Ekonomi

Undiksha,13 (2),

402-411

http://dx.doi.org/1

$0.23887 /$ jjpe.v13i

2.41105

\begin{abstract}
Research in the field of marketing management to optimize the formulation of promotions from customer satisfaction and knowledge sharing in realizing the economic welfare of local product business actors. The research was conducted in two cities in Indonesia that have a culture with batik products as an aesthetic regional icon in meeting customer needs. Batik has an appeal and philosophy which is a cultural heritage, economically it has value-added products to advance the region from increasing income. SDL research theory in providing a strategy to improve service quality in terms of promotion based on customer needs. The research was conducted on 300 batik entrepreneurs in Yogyakarta and in Palangka Raya. This type of quantitative research with statistical tools SPSS 24.0 shows significant positive results of customer satisfaction and knowledge sharing increasing the optimization of marketing promotions by $71 \%$. The implications of the research as a marketing strategy in increasing the income of local product business actors, from optimizing marketing promotions for the economic welfare of business actors.
\end{abstract}

Keywods: Customer Satisfaction; Knowledge Sharing; Promotion Formulation; Batik Products 


\section{PENDAHULUAN}

Kesejahteraan di negara Indonesia memiliki indikator penting sebagai ukuran keberhasilan, salah satunya dapat di ukur dari tingkat taraf hidup, seperti asumsi pelanggan terhadap produk lokal. Bentuk asumsi kepuasan pelanggan meliputi kebutuhan, rasa percaya pada produk, kualitas produk, keunikan produk dan harga produk yang sesuai. Dalam bidang pemasaran selain kepuasan dan kebutuhan pelanggan tujuan dari produk, juga untuk memberikan respons positif dasar sebagai kebijakan untuk ukuran keberhasilan strategi usaha .(Rafiqi et al., 2017)

Kebijakan pemasaran itu sendiri berorientasi pada upaya memberikan kepuasan kepada konsumen atau pelanggan melalui pemenuhan harapanharapan atau keinginan yang didasarkan pada kebutuhan (Dalimuthe, 2019). Kebijakan pemasaran yang dapat diarahkan pelaku usaha dalam upaya memenuhi harapan (keinginan dan kebutuhan) konsumen meliputi kebijakan yang mencakup produk, harga, promosi, dan distribusi. Salah satu hal yang dapat meningkatkan nilai tambah produk ialah ikonik dan estetika produk yang menonjol dibandingkan produk sejenis.

Kepuasan konsumen merupakan faktor yang dominan dan menentukan dalam mempertahankan maupun menumbuh kembangkan perusahaan (As' ari \& Suranto, 2021). Perusahaan harus mempunyai tujuan yang spesifik dan jelas agar bisa menetapkan kualitas. Fokus kualitas adalah konsumen, jadi pada dasarnya kepuasan konsumen dapat didefinisikan secara sederhana yaitu suatu keadaan dimana kebutuhan, keinginan, dan harapan pelanggan dapat terpenuhi melalui produk yang di beli. Berdasarkan penelitian sebelumnya, faktor-faktor yang mempengaruhi knowledge sharing dibuat dalam suatu perubahan untuk menjadi strategi usaha (Wuryanta, 2020). Pemilihan lokasi di kota Yogyakarta dan di kota Palangka Raya, di nilai mewakili dari pulau Kalimantan dan pulau jawa untuk strategi bisnis, dalam menjaga khasanah budaya warisan seperti batik yang menjadi ciri khas daerah sebagai wujud pelestarian produk lokal.

Model ini terdiri dari budaya organisasi, individu dan teknologi informasi untuk memeriksa kemampuan berbagi pengetahuan di antara karyawan/pekerja dalam organisasi sektor publik dan swasta (Rahayu et al., 2021). Faktor budaya organisasi terdiri dari sistem insentif dan sistem manajemen. Faktor individu terdiri dari perilaku individu dan harapan organisasi yang dapat memberikan perubahan baik. Kajian sebelumnya interaksi sosial dalam knowledge sharing menjadi hubungan timbal balik adalah hubungan yang dibangun seseorang dengan orang lain yang dalam proses kehidupan tersebut terbangun struktur social dalam kinerja (Karyon \& Ramdony, 2017), pada struktur sosial tersebut juga terbangun hubungan yang saling mempengaruhi antara satu dengan yang lainnya (Sinurat, 2018). Ciri-ciri dari knowledge sharing dalam jumlah pelaku dua orang atau lebih, ada komunikasi antar pelaku menggunakan symbol atau lambang, ada dimensi waktu (masa kini dan masa lalu), dan adanya tujuan yang hendak dicapai. Sedangkan ciriciri dari pemenuhan kebutuhan konsumen adalah dapat memberikan kesesuaian antara harapan dan kenyataan yang di dapatkan konsumen pada produk.

Pertukaran antara manfaat dan yang di bayarkan seimbang, menuntut pelaku usaha untuk melakukan inovasi dengan promosi yang terintegrasi sistem dengan teknologi. Dalam teori SDL Vargo \& Lusch (2017), perubahan pada bisnis dapat dilakukan dengan dominan logis lingkungan usaha dan kebutuhan konsumen, sehingga penelitian ini melalukan penguatan formulasi promosi pada produk lokal. Dari kajian empiris sebelumnya dapat menyatakan bahwa formulasi promosi adalah bentuk penyampaian dan informasi terkait, akan kelebihan dan kekurangan produk, serta cara pembayaran dan manfaat produk (Wuryanta, 2020).

Aktivitas knowledge sharing bisa terjadi berdasarkan asas timbal balik, aktivitas knowledge sharing yang dilakukan oleh karyawan akan memicu munculnya aktivitas yang sama dari rekan kerja. Artinya, 
p-ISSN : 2599-1418

e-ISSN : 2599-1426
Jurnal Pendidikan Ekonomi Undiksha

Vol. 13 No. 2 (2021) semakin banyak karyawan melakukan aktivitas tersebut maka semakin tinggi kesempatan akan munculnya respons aktivitas knowledge sharing. Berdasarkan teori service dominant logic, menyatakan bahwa kinerja dapat di tingkatkan dengan pengelolaan sistem pelayanan yang berbasis pada kepuasan konsumen. Strategi peningkatan dengan Customer Satisfying dan Knowledge Sharing Dalam Optimalisasi Formulasi Promotion Pemasaran Produk Lokal, perlu dilakukan di Yogyakarta dan Palangka Raya. Tujuan di lakukannya adalah untuk memberikan masukan brdasarkan hasil dalam meningkatkan pendapatan sebagai dampak positif dari dorongan kebutuhan konsumen dan keahlian pekerja mendapatkan informasi dari berbagi informasi dalam optimalisasi promosi (pemasaran produk).

Dalam penelitian ini menggunakan Teori Service Dominant Logic adalah sebuah konsep yang terkait dibidang pemasaran dengan sudut pandangnya bahwa pelayanan atau jasa merupakan suatu fundamental dalam kegiatan ekonomi, sedangkan uang, barang dan materi menjadi alat untuk mendapatkan manfaat dari produk yang di dapatkan konsumen (Vargo \& Lusch, 2017);(Setyowardhani \& Susanti, 2019). Dalam bisnis, pelayanan adalah ujung tombak dalam optimalisasi pendapatan dengan strategi usaha yang kompeten (Novansa \& Ali, 2017). Pada usaha yang memiliki produk, teori SDL adalah dasar untuk mendapatkan konsumen dengan memberikan pelayanan yang baik. Media teknologi informasi dan komunikasi dengan menerapkan promosi yang baik dan mampu di percaya akan memberikan kepuasan konsumen, terhadap produk. Pada kondisi perekonomian setelah pandemi, saat ini orientasi terhadap pelanggan merupakan strategi dapat dilakukan perusahaan, karena dengan memberikan pelayanan yang baik, maka pelanggan akan merasa puas dan bahagia, dengan demikian ia dapat memutuskan untuk membeli produk yang kita tawarkan (Karyon \& Ramdony, 2017).

\section{Definisi Kepuasan Pelanggan}

Kepuasan pelanggan bagi perusahaan merupakan tujuan dan menjadi sarana perusahaan, sebagai acuan keberhasilan perusahaan. Jumlah pesaing yang semakin banyak mengharuskan perusahaanperusahaan yang ada untuk mempunyai strategi khusus dalam bersaing, bertahan hidup serta berkembang (Nawari \& Shaferi, 2020). Definisi kepuasan adalah perasaan seperti senang atau kecewa seseorang yang timbul karena membandingkan kinerja yang dipersepsikan produk (atau hasil) terhadap ekspektasi mereka. Menurut Dewi \& Febriani (2021) kepuasan pelanggan adalah perbedaan antara harapan dan kinerja atau hasil yang dirasakan. Dari kajian empiris sebelumnya, dapat disimpulkan bahwa kepuasan pelanggan adalah tujuan dan sasaran suatu perusahaan dengan memberikan pelayanan yang baik kepada pelanggan. Sehingga lewat pelayanan tersebut pelanggan akan mengevaluasi terhadap kesesuaian dengan harapan dan keinginannya melalui sikap dan perasaan senang atau kecewa.

\section{Faktor-faktor dalam Kepuasan Pelanggan}

Faktor utama yang dapat menjadi ukuran kepuasan dari pelanggan adalah apabila pelanggan merasa apa yang diinginkan terpenuhi dengan maksimal. Menurut Prasetyaningtyas et al., (2020), pelanggan merasa puas jika harapan dan hasil yang di dapatkan berbanding/terpenuhi. Ada lima dimensi utama kepuasan pelanggan (Wuryanta, 2020) meliputi: dimensi pertama, adalah kualitas produk atau jasa, pelanggan akan puas bila setelah membeli dan menggunakan produk/jasa tersebut, ternyata kualitasnya baik. Dimensi kedua, adalah harga, pelanggan yang sensitif biasanya harga murah adalah sumber kepuasan yang penting karena mereka akan mendapatkan value form money. Dimensi ketiga, adalah service quality, sangat tergantung pada tiga hal, yaitu sistem, teknologi dan manusia. Dimensi keempat adalah emotional factor, persepsi pelanggan memegang peranan penting karena adanya emotional value yang diberikan brand tertentu. Dimensi kelima adalah kemudahan 
p-ISSN : 2599-1418

e-ISSN : 2599-1426

untuk mendapatkan produk atau jasa tersebut. Kepuasan pelanggan dapat di ukur dengan beberapa indikator yaitu: 1). Telah memenuhi harapan pelanggan. 2). Berdasarkan pengalaman, pelanggan merasa senang. 3). Pelanggan Percaya berbelanja dapat menguntungkan (memuaskan).

Ditinjau dari konsep perilaku konsumen dalam pengambilan keputusannya, bahwa konsumen yang baik dalam pengambilan keputusan harus melalui beberapa tahap (proses), antara lain mencari informasi tentang perusahaan atau produk yang dapat memenuhi kebutuhan yang sama, menilai dari beberapa alternatif, mencoba sebagai pengambilan keputusan temporer, jika sesuai dengan harapan maka akan menjadi pelanggan yang setia. Konsep kepuasan konsumen menurut Putra et al., (2020), bahwa konsumen setelah melakukan pembelian akan melakukan perbandingan antara harapan sebelum melakukan pembelian dengan keadaan sesungguhnya setelah melakukan pembelian. Apabila harapan tidak sesuai dengan yang diharapkan, maka konsumen akan merasa tidak puas.

Tetapi perlu di pahami bahwa kepuasan setiap orang berbeda-beda, karena dilandasi keinginan dan kebutuhan yang berbeda-beda pula (Rofaida et al., 2019). Orang memutuskan untuk berlangganan karena didorong adanya kebutuhan dan keinginan yang harus dipenuhi, dan keputusan berlangganan paling tidak salah satu dari banyaknya variabel yang dapat memenuhi harapan pelanggan.

Masalah pandemic COVID-19 saat ini berdampak pada penurunan pendapatan karena konsumen banyak beraktifitas dari rumah. Bagi pelaku usaha rumah makan hal ini harus disiasati agar usaha dapat terus bertahan di tengah kondisi dengan melakukan control kualitas produk (Kristinae et al., 2019). Mendapatkan informasi yang menyangkut kepentingan konsumen akan efektif dan efisien dengan knowledge sharing bersama pelaku usaha signifikan meningkatkan formulasi promosi.

\section{Knowledge sharing}

Jurnal Pendidikan Ekonomi Undiksha

Vol. 13 No. 2 (2021)

Knowledge sharing adalah suatu keyakinan seseorang dalam mengartikan dan mengelola sekumpulan informasi dengan mengkombinasikan informasi tersebut dengan informasi lainnya, menerjemahkan, dan kemudian mengambil suatu tindakan (Rumagit \& Rengkung, 2019). Knowledge sharing adalah proses timbal balik dimana individu saling bertukar pengetahuan (tacit and explicit knowledge) dan secara bersama-sama menciptakan pengetahuan (solusi) baru. Mengkomunikasikan pengetahuan kepada orang lain apa yang dimiliki dari personal intellectual seseorang, dan mengumpulkan pengetahuan merujuk pada berkonsultasi dengan rekan kerja dengan membagi informasi atau intellectual yang mereka miliki. Melalui aktivitas berbagi pengetahuan maka individu yang melakukannya akan memperoleh keuntungan individual (Yahya \& Gunawan, 2021). Bagi mereka seorang pegawai maka kemampuan belajar akan meningkat dengan berbagai cara seperti externalization, internalization, socialization, dan Community of practice (CoP) (Hartwig et al., 2021) bisnis organisasinya.

Ketika pegawai sudah mulai melakukan berbagi pengetahuan dan melakukan pembelajaran secara berkelanjutan, maka ketika mendapatkan pengetahuan tentang perubahan kondisi kerja, pegawai tersebut sudah lebih siap dibandingkan pegawai yang tidak ikut aktif dalam proses manajemen pengetahuan. Perubahan kondisi kerja maupun organisasi yang begitu cepat dapat diimbangi oleh pegawai yang mengimplementasikan proses manajemen pengetahuan, sehingga dapat mengurangi jumlah pegawai yang keluar akibat tidak dapat mengikuti perkembangan

\section{Definisi Promosi Produk}

Promosi merupakan suatu upaya dalam menginformasikan atau menawarkan produk atau jasa yang bertujuan untuk menarik calon konsumen agar membeli atau mengkonsumsinya, sehingga diharapkan dapat meningkatkan volume penjualan (Buchari \& Darmawan, 2020). Sedangkan 
p-ISSN : 2599-1418

e-ISSN : 2599-1426
Jurnal Pendidikan Ekonomi Undiksha

Vol. 13 No. 2 (2021) menurut Ong (2020), mengemukakan bahwa promosi merupakan kegiatan yang ditujukan untuk mempengaruhi konsumen agar mereka dapat menjadi kenal akan produk yang ditawarkan oleh perusahaan kepada mereka yang kemudian mereka menjadi senang lalu membeli produk tersebut. Selanjutnya menyatakan bahwa promosi adalah suatu kegiatan yang dilakukan pemasar untuk menyampaikan informasi mengenai produknya dan membujuk konsumen agar mau membelinya (Revan et al., 2021; Prasetyaningtyas et al., 2020). Berdasarkan kajian empiris dan teori SDL, meningkatkan pemasaran membutuhkan strategi yang berdasarkan pada kebutuhan konsumen (Vargo \& Lusch, 2017; Buchari \& Darmawan, 2020).

Secara garis besar, promosi adalah kegiatan menginformasikan mengenai produk dan jasa kepada konsumen agar dapat dikenal dan membujuk konsumen untuk dapat membeli produk dan jasa.

Tujuan utama promosi ialah memberi informasi, menarik perhatian dan selanjutnya memberi pengaruh meningkatnya penjualan (Wuryanta, 2020). Tujuan formulasi promosi adalah untuk mendapatkan perhatian, pengajaran, untuk meningkatkan, membujuk, dan menyakinkan. Suatu kegiatan promosi jika dilaksanakan dengan baik dapat mempengaruhi konsumen mengenai dimana dan bagaimana konsumen membelanjakan pendapatannya. Promosi dapat membawa keuntungan baik bagi produsen maupun konsumen.

Formulasi promosi memiliki tujuan umum dan tujuan khusus, yang akan dijelaskan sebagai berikut: 1). Tujuan umum, bersumber pada tujuan komunikasi pemasaran, yaitu untuk mempercepat respon pasar yang ditargetkan. 2). Tujuan khusus. a). Bagi konsumen (consumer promotion), untuk mendorong konsumen antara lain untuk lebih banyak menggunakan produk, unit pembeli produk dalam unit yang besar, mencoba merek yang dipromosikan, dan untuk menarik pembeli merek lain yang bersaing dengan produk yang sedang dipromosikan. b). Bagi pengecer (trade promotion), membujuk pengecer untuk menjual barang produk baru, menimbun lebih banyak persediaan barang menimbun barangbarang dipromosikan dan memperoleh jalur pengecer

baru. c). Bagi wiraniaga (sales force promotion), untuk memberi dukungan atau produk atau produk baru, untuk merangsang mereka mencari pelanggan baru dan mendorong penualan musim semi.

Periklanan adalah segala bentuk penyajian dan promosi ide, barang atau jasa secara nonpersonal oleh suatu sponsor tertentu yang memerlukan pembayaran. Definisi iklan adalah elemen komunikasi pemasaran yang persuasif, nonpersonal, dibayar oleh sponsor dan disebarkan melalui saluran komunikasi massa untuk mempromosikan pemakaian barang, atau jasa (Rezki \& Hapsari, 2019). Periklanan adalah merupakan alat utama bagi perusahaan untuk mempengaruhi konsumennya. Periklanan ini dapat dilakukan oleh pengusaha lewat surat kabar, radio, majalah, televisi ataupun dalam bentuk poster-poster yang dipasang, untuk meningkatkan pemasaran produk (Wahyudi \& Nugroho, 2018). Sehingga memiliki tujuan untuk meningkatkan penjualan produk.

Berdasarkan teori dan kajian empiris sebelumnya, maka hipotesis penelitian yang di ajukan ialah:

$\mathrm{H1}$ : Customer Satisfying signifikan positif meningkatkan Promotion

H2: Knowledge Sharing signifikan positif meningkatkan Promotion

H3: Customer Satisfying dan Knowledge Sharing, signifikan positif meningkatkan Promotion, secara simultan.

\section{METODE}

Penelitian kuantitatif dengan uji analisis regresi berganda menggunakan penyebaran kuesioner terhadap 300 pelaku usaha produk lokal (pakaian jadi motif batik) di Pasar Bering Harjo Yogyakarta dan di Pasar Kameloh Palangka Raya. Instrument penelitian di uji validitas dan reliabilitas, untuk mendapatkan hasil penelitian tidak bias. Jenis data penelitian ini adalah data 
p-ISSN : 2599-1418

e-ISSN : 2599-1426

primer yang merupakan hasil langsung dari responden mengenai persepsi secara langsung sebagai informasi yang dapat diandalkan dalam penelitian ini. Pengujian untuk interprestasi hasil di lakukan dengan alat statistic SPSS 24.0. Menurut Darung \& formulasi Kristinae et al., (2019) sebagai berikut: $\mathrm{Y}=\mathrm{a}$ (konstanta)+ $\mathrm{b}_{1} \mathrm{X}_{1}$ (Customer Satisfying) $+\mathrm{b}_{2} \mathrm{X}_{2}$ (Knowledge Sharing) $+e$

Keterangan:

$\mathrm{Y}=$ Formulasi Promotion

$\mathrm{X}_{1}=$ Customer Satisfying signifikan dan positif untuk meningkatkan Formulasi Promotion

$\mathrm{X}_{2}=$ Knowledge Sharing signifikan dan positif untuk meningkatkan Formulasi Promotion

$\mathrm{b}=$ koefisien regresi

\section{HASIL DAN PEMBAHASAN}

Berdasarkan kuesioner dari 300 responden dan hasil analisa data tampak dari tabel 1 , bahwa pengaruh $X 1$ dan $X 2$ terhadap $Y$ berpengaruh signifikan sebesar adjusted R Square yaitu $71,2 \%$. Hasil ini menyatakan bahwa Customer Satisfying sebagai X1 dan Knowledge Sharing X2 sangat penting untuk meningkatkan Formulasi Promotion. Dari hasil uji analisis, hasil menunjukkan pentingnya variabel independen dan arah yang signifikan positif
Jurnal Pendidikan Ekonomi Undiksha

Vol. 13 No. 2 (2021)

Kristinae, (2021), hasil penelitian berdasarkan kuesioner dan di uji regresi linier dapat memberikan implikasi hasil yang terarah. Alat statistic SPSS memiliki persamaan regresi linier berganda dengan

masing-masing variabel $\mathrm{X} 1$ dan $\mathrm{X} 2$ melalui indikatornya dapat meningkatkan formulasi promotion pemasaran produk lokal di pasar bering Harjo Yogyakarta dan di pasar Kameloh Palangka Raya.

Dalam memberikan interprestasi data dari hasil penelitian, maka dilakukan pengujian selanjutnya dengan uji t atau uji analisis secara parsial dalam uji hubungan variabel $\mathrm{X}$ masing-masing terhadap $\mathrm{Y}$. Hasil pengujian, pada tabel 2 , hasil $\mathrm{H}_{1}$ menunjukkan hubungan yang signifikan dan positif Customer Satisfying dapat meningkatkan formulasi Promotion sebesar t-hitung $2.137>0,675$ t-tabel dengan signifikan $0,00<0,05$. Semakin tingginya pelaku usaha mampu mengidentifikasi dan menerapkan sistem dan teknologi promosi yang dibutuhkan konsumen untuk mewujudkan kepuasan konsumen, maka berdampak positif dan signifikan mendorong peningkatan promosi pemasaran produk lokal. Hasil penelitian ini dapat menjadi strategi usaha dalam meningkatkan promosi dari kepuasan konsumen.

Tabel 1. Output Regresi Nilai R Square

\begin{tabular}{ccccc}
\hline Model & $\mathrm{R}$ & $\mathrm{R}$ Square & Adjusted R Square & $\begin{array}{c}\text { Std. Error of the } \\
\text { Estimate }\end{array}$ \\
\hline 1 & $.826^{\mathrm{a}}$ & .793 & .712 & .514 \\
\hline
\end{tabular}

Sumber : Data diolah,2021

Tabel 2. Output Regresi Linier Berganda Secara Parsial

\begin{tabular}{|c|c|c|c|c|c|}
\hline \multirow[t]{2}{*}{ Model } & \multicolumn{2}{|c|}{$\begin{array}{l}\text { Unstandardized } \\
\text { Coefficients }\end{array}$} & $\begin{array}{c}\text { Standardize } \\
d \\
\text { Coefficients }\end{array}$ & \multirow[t]{2}{*}{$\mathrm{t}$} & \multirow[t]{2}{*}{ Sig. } \\
\hline & B & Std. Error & Beta & & \\
\hline (Constant) & .112 & .029 & & .164 & .004 \\
\hline
\end{tabular}




\begin{tabular}{|c|c|c|c|c|c|}
\hline Customer Satisfying (X1) & .772 & .043 & .615 & 2.137 & .070 \\
\hline Knowledge Sharing (X2) & .543 & .057 & .422 & 2.861 & .000 \\
\hline
\end{tabular}

a. Dependent Variable: Formulasi Promotion

Sumber ; Data diolah,2021

Tabel 3. Output Regresi Berganda Pengaruh X1 dan X2

\begin{tabular}{|c|c|c|c|c|c|c|}
\hline \multirow{2}{*}{\multicolumn{2}{|c|}{ Model }} & \multirow{3}{*}{$\begin{array}{c}\begin{array}{c}\text { Sum of } \\
\text { Squares }\end{array} \\
181.394\end{array}$} & \multicolumn{3}{|c|}{ Mean } & \multirow{3}{*}{$\frac{\text { Sig. }}{.000^{k}}$} \\
\hline & & & df & Square & $\mathrm{F}$ & \\
\hline \multirow[t]{3}{*}{1} & Regression & & 2 & 19.752 & 29.163 & \\
\hline & Residual & 69.132 & 298 & .284 & & \\
\hline & Total & 250.526 & 300 & & & \\
\hline
\end{tabular}

a. Dependent Variable : Formulasi Promotion

Sumber : Data diolah,2021

Hasil uji dari table 3 , tampak hasil diperoleh f-hitung sebesar 29,103 dengan nilai signifikan $0.00^{\mathrm{b}}$ yang menunjukkan bahwa ada hubungan linier antara Customer Satisfying (X1) dan Knowledge Sharing (X2) terhadap Formulasi Promotion (Y). Hipotesis $\mathrm{H}_{3}$ dalam penelitian yang menyatakan bahwa Customer Satisfying (X1) dan Knowledge Sharing (X2) dapat meningkatkan Formulasi Promotion diterima berdasarkan hasil analisa data. Hasil ini kemudian kembali dicek berdasarkan dari hasil f-tabel untuk responden 300 responden, hasilnya f-tabel sebesar 3,87 < 29,163 f-hitung artinya signifikan positif, variabel $\mathrm{X} 1$ dan $\mathrm{X} 2$ dapat meningkatkan formulasi promosi pemasaran produk lokal. Hasil penelitian membuktikan bahwa, variabel Customer Satisfying $\left(\mathrm{X}_{1}\right)$ dan Knowledge Sharing $\left(\mathrm{X}_{2}\right)$, dalam meningkatkan formulasi promotion melalui parameter indikatornya hasil analisa sangat baik sebagai strategi bisnis, untuk perubahan yang berdampak baik dalam meningkatkan promosi. Kebutuhan konsumen dari promosi yang mampu menyajikan kejelasan manfaat dan kelebihan produk, dapat dipercaya dan mudah cara mencari produk, serta kejelasan harga sangat penting sebagai formulasi promosi pemasaran produk lokal.
Selanjutnya kebaikan manfaat dari kemampuan pelaku usaha dalam berbagi pengetahuan yang mengutamakan perubahan dan perbaikan sistem dengan menjalin hubungan serta mendapatkan informasi pihak-pihak terkait untuk mendapatkan masukan yang positif mendorong promosi produk. Tujuan dari penelitian dalam meningkatkan formulasi promosi produk dari identifikasi kepuasan konsumen dan berbagi pengetahuan berdasarkan hasil sangat penting untuk memberikan peluang pada usaha lokal meningkatkan penjualan dan pendapatan. Hasil dapat diterapkan sebagai metode bisnis berbasis konsumen dan pengetahuan, hasil ini juga mengkonfimasi kajian empiris sebelumnya mengenai kemudahan dan metode dalam meningkatkan formula promosi (Ong, 2020; Rahayu et al., 2021; Dewi \& Febriani, 2021)). Hasil penelitian secara keseluruhan memberikan gambaran bahwa di lapangan pada UKM di Yogyakarta dan UKM di Palangka Raya, membutuhkan strategi bisnis dari kemampuan pelaku usaha dalam menjalin relationship yang memberikan masukan dari knowledge sharing untuk membangun formulasi promosi berbasis pada lingkungan bisnis dan kebutuhan konsumen. Selain itu secara eksiting hasil di 
p-ISSN : 2599-1418

e-ISSN : 2599-1426

lapangan dan analisa kepuasan konsumen sekarang membutuhkan tingkat promosi yang sesuai dengan harapan yang berbanding sama dengan kenyataan. Maka hasil bermanfaat untuk dapat di jadikan masukan dalam meningkatkan formulasi promosi berbasis dari knowledge sharing dan customer satisfying.

\section{SIMPULAN DAN SARAN}

Kepuasan konsumen bukan saja menjadi tujuan dalam usaha. Berdasarkan hasil kepuasan konsumen dapat menjadi pengaruh bebas dalam memberikan dorongan peningkatan formulasi promosi yang berbasis trend, yang berdampak positif dalam penjualan dan peningkatan pendapatan. Metode bisnis berbasis konsumen dalam memberikan perubahan yang menjadi strategi dari identifikasi kebutuhan konsumen dalam promosi terkini. Berbagi pengetahuan dengan sesama pekerja dari hasil membuktikan, dapat menjadi masukan bermanfaat mengenai sistem, model produk maupun minat konsumen, agar produk dapat di terima konsumen secara luas.

Formulasi promosi sangat penting dalam bisnis sebagai pemasaran produk. Keberhasilan promosi harus selaras dengan produk yang ditawarkan (Dewi \& Febriani, 2021). Berdasarkan hasil menunjukkan promosi harus memiliki ciri yaitu: jelas, sesuai produk, menarik dan memberikan informasi yang mudah dimengerti konsumen. Peningkatan penjualan produk pada local product, dapat di lakukan dengan menguatkan sistem pemasaran. Salah satunya ialah dengan metode promosi yang berbasisi konsumen. Seperti saat ini dapat di lakukan dengan digitalisasi (e-promotion). Banyak keuntungan yang didapatkan dari hasil, yaitu: informasi cepat diterima konsumen, cara pesanan jelas dan mudah, bahasa yang di gunakan jelas dan menarik. Implikasi penelitian dari hasil memberikan makna bahwa konsumen dapat menjadi tolak ukur untuk meningkatkan kegiatan dalam formulasi promosi pemasaran produk lokal, dikenal masyarakat lebih luas dan pengembangan produk lebih cepat, yang berdampak meningkatkan penjualan produk.
Jurnal Pendidikan Ekonomi Undiksha

Vol. 13 No. 2 (2021)

Penelitian ini dilakukan pada produk lokal khusus batik yang memiliki philosofi produk di pasar Bering Harjo di Yogyakarta dan pasar Kameloh di Palangka Raya. Sehingga value added produk dapat melestarikan budaya. Saran penelitian, yang perlu di berikan deskripsi produk batik dalam promosi secara digital. Dalam memperkaya hasil teori Service Dominant Logic, dapat terus digunakan untuk memperkaya penelitian dalam bidang manajemen di skala kecil menengah. Pada penelitian selanjutnya diharapkan ada penambahan variabel kinerja pemasaran, agar implikasi hasil dengan strategi bisnis dapat menjadi hasil relevan dibidang manajemen pemasaran.

\section{DAFTAR PUSTAKA}

As' ari, D., \& Suranto, I. (2021). Model Pemasaran Peningkatan Minat Beli Dan Kepuasan Konsumen Pada Produk Gitar (Studi di Sentra Industri Gitar Mancasan, Baki). Doctoral Dissertation, Universitas Muhammadiyah Surakarta).

Buchari, R. A., \& Darmawan, I. (2020). Peningkatan Potensi Kewirausahaan Produk Lokal Melalui Pemasaran Digital Desa Cikeruh Jatinangor. Sawala. Jatinangor. Sawala: Jurnal Pengabdian Masyarakat Pembangunan Sosial, Desa Dan Masyarakat, 1(2), 51.

Dalimuthe, R. F. (2019). The effect of entrepreneurial mindset, digital training and supervision on the competitiveness of small and medium enterprises (SME) for Women. Journal of International Women's Studies, 20(9), 121-131.

Darung, F., \& Kristinae, V. (2021). Strategi Bisnis Dalam Meningkatkan Kinerja Bisnis Rumah Makan di Kalimantan Tengah. JURNAL ILMU MANAJEMEN, 11(2), 69-78.

Dewi, W. W. A., \& Febriani, N. S. (2021). Webqual 4.0 untuk Meningkatkan Keterlibatan Pengusaha UMKM di Indonesia (Studi pada www. berrybenka. com sebagai Platform ECommerce Produk lokal UMKM (Usaha Mikro Kecil Menengah). JCommsciJournal Of Media and Communication 
Science, 4(2), 80-88.

Hartwig, K., Saldern, L. Von, \& Jacob, F. (2021). The journey from goodsdominant logic to service-dominant logic: A case study with a global technology manufacturer. Industrial Marketing Management, 95, 85-98.

Karyon, O., \& Ramdony, J. (2017). Implementasi Strategi Berbasis Resources dan Knowledge Sharing pada UMKM di Provinsi Jawa Barat. Prosiding, 7(1).

Kristinae, V., Sambung, R., \& Sahay, M. (2019). The role of entrepreneurial orientation in product innovation in emerging markets on the local products. Oradea Journal of Business and Economics, 4(2), 35-44.

Nawari, A. T., \& Shaferi, I. (2020). The Benefit of SME Online Promotion Strategy for Renew Product in New Era. Sustainable Competitive Advantage (SCA), 10(1), 678-683.

Novansa, H., \& Ali, H. (2017). Purchase Decision Model: Analysis of brand image, brand awareness and price (Case study SMECO Indonesia SME products). Saudi Journal of Humanities and Social Sciences, 2(8), 25-36.

Ong, D. (2020). Analisa Penggunaan Sistem Sosial Media Terhadap Dampak Pemasaran Penjualan Produk Pada Umkm. Respati, 15(2), 26-36.

Prasetyaningtyas, W. S., Raharjo, K., \& Afrianty, T. W. (2020). Pengaruh kepemimpinan transformasional dan budaya organisasi terhadap knowledge sharing dan kepuasan kerja. Jurnal Ekonomi Dan Bisnis, 13(2), 379-399.

Putra, A. B. N. R., Winarno, A., Purnomo, A., Asfani, K., Tuwoso, T., \& Ramadani, A. H. (2020). Peningkatan Sektor Promosi Wisata Area Perkemahan Bedengan Dengan Tourism Dispaly-Gate Berteknologi Smart-Led di Kecamatan Dau Kabupaten Malang. . . E-Prosiding Hapemas, 1(1), 235-244.

Rafiqi, Y., Rahmat, B. Z., \& Joni, J. (2017). Model Wirausaha Muda Berbasis Kearifan dan Sumber Daya Lokal. Jurnal Pengabdian Siliwangi, 3(2).

Rahayu, F., Barkah, C., Chan, A., \&
TRESNA, P. W. (2021). Analisis Kepuasan Konsumen Terhadap Produk Sambal Kemasan Untuk Formulasi Perbaikan Strategi Produk BISMA. Jurnal Bisnis Dan Manajemen, 15(1), 47-55.

Revan, H., RENI, Y., \& Irda, I. (2021). Pengaruh Kualitas Produk dan Promosi Terhadap Loyalitas Pelanggan Dengan Kepuasan Pelanggan Sebagai Variable Intervening (Study Kasus Pada Pelanggan Distro Skaters Plaza Andalas Padang). (Doctoral Dissertation, Universitas Bung Hatta).

Rezki, M. A., \& Hapsari, D. R. (2019). Efektivitas Strategi Promosi Produk Kopi Lokal di Rumah Kopi Ranin. Jurnal KMP. Jurnal Komunikasi Pembangunan, 17(1), 38-54.

Rofaida, R., Suryana, S., \& Krishna, A. (2019). Strategi Pengembangan Corporate Entrepreneurship pada Industri Kreatif Digital di Jawa Barat. In Prosiding Seminar Nasional IImu Sosial Dan Teknologi (SNISTEK), 2, 187-192.

Rumagit, G. A. J., \& Rengkung, L. R. (2019). Tingkat Kepuasan Pelanggan "SANG PISANG” di Kota Manado. AGRISOSIOEKONOMI, 15(1), 109-116.

Setyowardhani, H., \& Susanti, H. (2019). Optimalisasi Media Sosial Sebagai Alat Promosi Untuk Desa Wisata Lebakmuncang. Jurnal Pengabdian Kepada Masyarakat, 3.

Sinurat, M. T. (2018). Pengaruh Bauran pEMASARAN Jasa Terhadap Kepuasan Konsumen Yang Berwisata ke Pantai Pasir Putih Parbaba (Studi Kasus Pantai Pasir Putih Parbaba).

Vargo, S. L., \& Lusch, R. F. (2017). Servicedominant logic 2025. International Journal of Research in Marketing, 34(1), 46-67.

Wahyudi, W., \& Nugroho, P. (2018). Transfer Pengetahuan, Inovasi dan Produktivitas Dalam Pembentukan Daya Saing Lokal Klaster Industri ( Studi Kasus: Sentra Industri Shuttlecock, Desa Sumengko Kecamatan Sukomoro Kabupaten Nganjuk). Doctoral Dissertation, UNIVERSITAS DIPONEGORO. 
Wuryanta, A. E. W. (2020). Aktivitas Promosi Media Sosial Instagram dan Sikap Konsumen Muda Produk Batik Lokal. Warta Ikatan Sarjana Komunikasi Indonesia, 3(02), 91-102.

Yahya, E. S., \& Gunawan, A. I. (2021). Apakah Atribut Produk Coffee Shop Mampu Mendorong Minat Pembelian? Studi Kasus Pada Pembelian Kopi Lokal. Edunomic: Jurnal IImiah Pendidikan Ekonomi Fakultas Keguruan Dan IImu Pendidikan, 9(2), 200-201. 